\title{
Application of SDBR with DFIG to Augment Wind Farm Fault Ride Through
}

\author{
K.E. Okedu ${ }^{1 *}$, S.M. Muyeen ${ }^{2}$, Rion Takahashi ${ }^{1}$, and Junji Tamura ${ }^{1}$ \\ ${ }^{1}$ Department of Electrical and Electronic Engineering, Kitami Institute of Technology, Japan \\ ${ }^{2}$ Department of Electrical Engineering, The Petroleum Institute, Abu Dhabi, U.A.E \\ E-mail: kenokedu@yahoo.com
}

\begin{abstract}
This paper proposes an application of series dynamic braking resistor (SDBR) connected to the stator side of a doubly fed induction generator (DFIG), for enhancing fault ride through (FRT) capability. Two schemes were investigated; the first scheme uses a bypass switch to show the effect of the SDBR magnitude, while the second one uses a circuit breaker to determine the best insertion time and duration of operation of the SDBR, considering the best SDBR resistance obtained in the first scheme. The proposed schemes were then applied to stabilize a DFIG. Simulation analysis by using PSCAD/EMTDC shows that the SDBR can substantially improve the FRT of the DFIG. It also shows that the size of the SDBR should be determined carefully because large value may worsen the system performance during a grid fault.
\end{abstract}

\section{INTRODUCTION}

Fault ride through (FRT) is required to be considered nowadays for connection of large wind farms in most power systems. The FRT refers to the capability of generation plant to remain connected with being dynamically stable, and offer network support during a serious voltage disturbance on the transmission network. The FRT compliant wind farm must remain connected to the power system and actively contribute to the system stability during a wide range of network fault scenarios [1].

Among wind power generators, the doubly fed induction generator (DFIG) is gaining popularity due to its variable wind speed tracking performance and relatively low cost based on the use of partially rated power converter in its rotor circuit.

However, during a grid fault, the DFIG is vulnerable to grid disturbances because the stator windings are connected directly to the grid while the rotor windings are buffered from the grid via a partially-rated frequency converter [2-5]. In [1, 6], a crowbar was used to improve the FRT of DFIG, while in $[7,8]$, a DC-chopper was used. The strategy of combining the crowbar system and the DC-chopper system was previously studied in [9], while a comparative study of both protection systems was reported in [10]. A static series compensator (SSC) or a dynamic voltage restorer (DVR) [11-13] and STATCOM [14] were used to improve the FRT of the DFIG. A series dynamic braking resistor (SDBR) was used to improve the FRT of large wind farms composed of induction generators in [15], while in [16] the SDBR was connected to the rotor side converter of the DFIG to improve its FRT. The use of superconducting fault current limiter (SFCL) [17], passive resistance network [18], and series antiparellel thyristor [19] connected to the stator side of a grid connected DFIG, have been reported in the literature.
A small size SBDR can be inserted in series with the stator circuit of the DFIG through the control of power electronic switches to balance the active power, which eventually improves the wind generator stability during a grid fault and is less expensive than the SFCL, passive resistance network and series antiparallel thyristor.

In this paper, the effect of the magnitude of the SDBR is investigated along its insertion time and duration of operation. The simulation results in PSCAD/EMTDC [20] show that the size of the SDBR should be determined carefully because large value may worsen the system performance in stabilizing the DFIG, hence the small value are used to determine the best insertion time of the SDBR. The shorter duration of operation of the SDBR gives a better response of the DFIG system during a grid fault. This work attempts to improve further the overall performance of DFIG during a grid disturbance when it is connected to a fixed speed wind turbine (FSWT) driven by an induction generator (IG). Hence, a new control strategy using a DC-chopper inserted into the DC-link between the power converters of the DFIG and a small value of SDBR connected in series in the stator of the DFIG, is proposed, the former of which acts as a damping load to protect the DC-link voltage during a grid fault.

\section{WIND TURBINE MODEL}

The dynamics interaction involving forces from the wind and the response of wind turbine determines the amount of kinetic energy that can be extracted. The aerodynamic torque and the mechanical power of a wind turbine are given by [2123].

$$
\begin{aligned}
& T_{M}=\frac{\pi \rho R^{3}}{2} V_{w}{ }^{2} C_{t}(\lambda)[\mathrm{NM}] \\
& P_{M}=\frac{\pi \rho R^{2}}{2} V_{w}{ }^{3} C_{p}(\lambda)[\mathrm{W}]
\end{aligned}
$$

Where $\rho$ is the air density, $\mathrm{R}$ is the radius of the turbine, $V_{w}$ is the wind speed, $C_{p}(\lambda, \beta)$ is the power coefficient given by

$$
C_{p}(\lambda, \beta)=0.5\left(\Gamma-0.02 \beta^{2}-5.6\right) e^{-0.17 \Gamma}
$$

The relationship between $C_{t}$ and $C_{p}$ is

$$
C_{t}(\lambda)=\frac{C_{p}(\lambda)}{\lambda}
$$




$$
\begin{aligned}
& \lambda=\frac{\omega_{r} R}{V_{w}} \\
& \Gamma=\frac{R}{\lambda} \frac{(3600)}{(1609)}
\end{aligned}
$$

Where $\lambda$ is the tip speed ratio. The wind turbine characteristics [24] for both IGs and DFIGs are shown in Figs. 1 and 2 respectively. In Fig. 2, the power capture characteristic of the turbine and the rotor speed are shown. The dotted lines show the locus of the maximum power point of the turbine which is used to determine the reference of active power output $P_{\text {ref }}$. Equations (7) and (8) are used to calculate the reference of the active power output $P_{\text {ref }}$ as shown in section A of Fig. 3. The optimum rotor speed $\omega_{\text {ropt }}$ is given in eqn. (9). The operation range of the rotor of DFIG is chosen from $0.7 \mathrm{pu}$ to $1.3 \mathrm{pu}$ as shown in the wind turbine characteristics in Fig. 2.

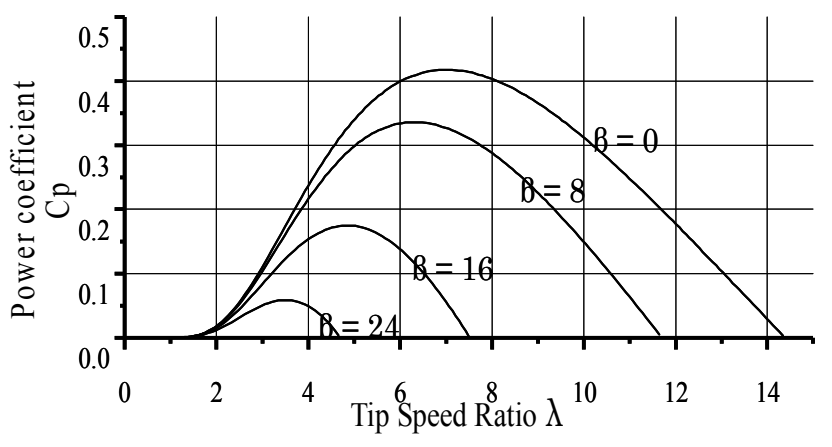

Fig. $1 \mathrm{C}_{\mathrm{P}}-\lambda$ curves for different pitch angles (for IG)

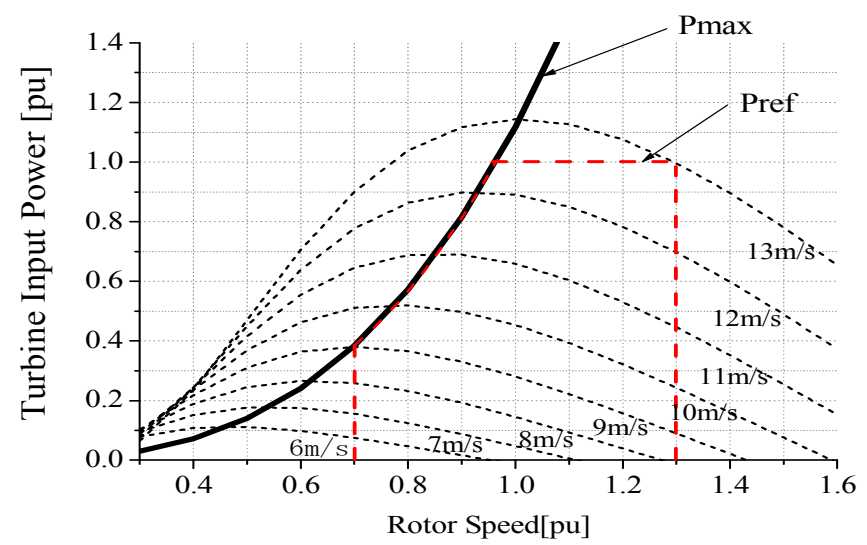

Fig.2 Turbine characteristic with maximum power point tracking (for DFIG)

$$
\begin{aligned}
& P_{\text {ref } 1}=0.1571 V_{w}-1.035[\mathrm{pu}] \\
& P_{\text {ref } 2}=0.2147 V_{w}-1.668[\mathrm{pu}] \\
& \omega_{\text {ropt }}=0.0775 V_{w}[\mathrm{pu}]
\end{aligned}
$$

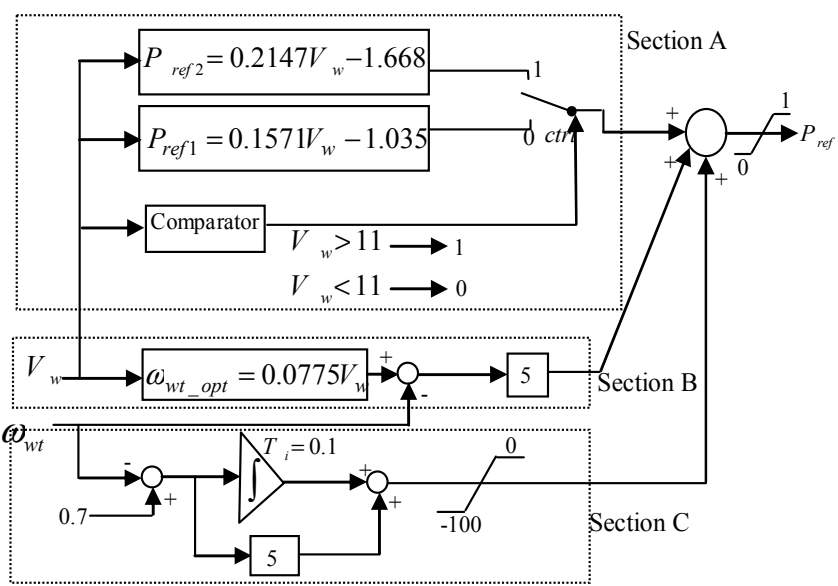

Fig. 3 Control block to determine active power reference $P_{r e f}$

\section{MODEL SYSTEM}

The model system for this study is shown in Fig. 4, where a DFIG and an IG are connected to an infinite bus through their point of common coupling (PCC).

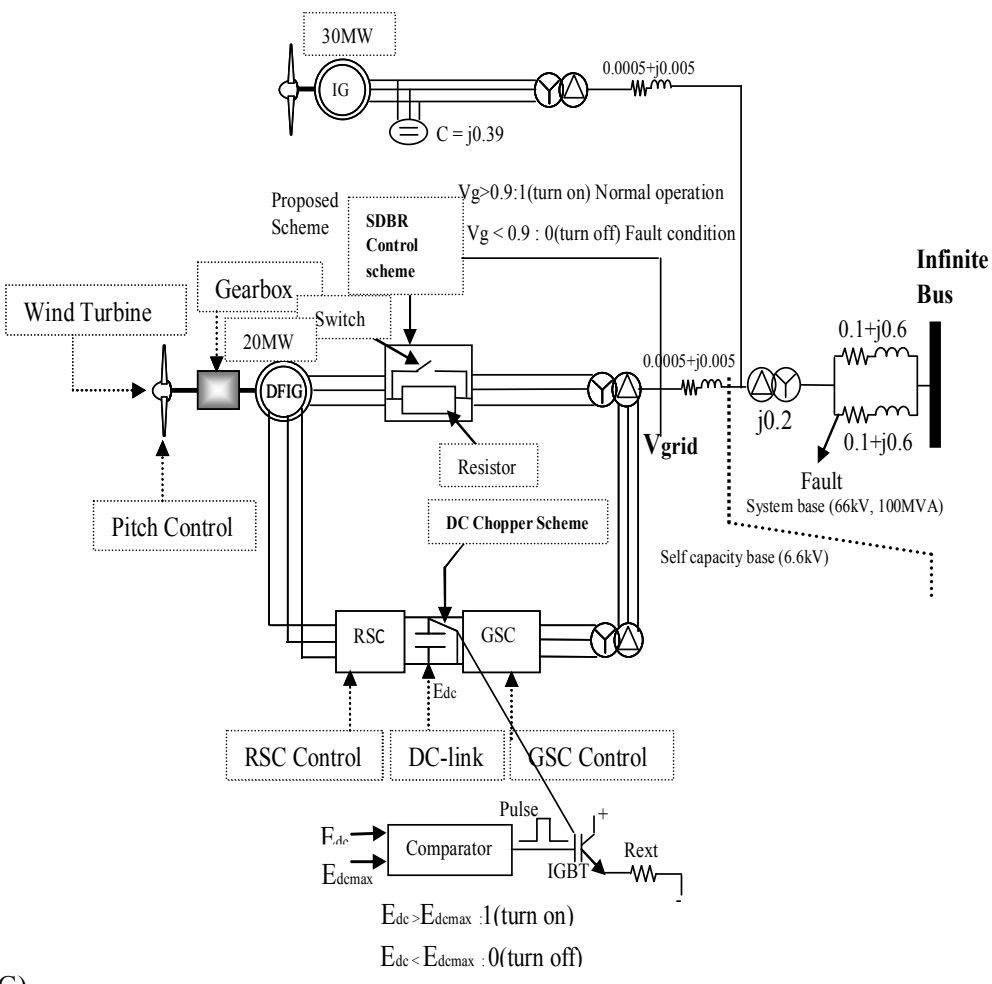

Fig. 4 Model system

The generator parameters and excitation circuits are given in [10]. The SDBR is connected to the stator circuit of the DFIG as shown in Fig. 4. A DC chopper braking resistor is also used in the proposed system for protecting the DC-link circuit during grid fault. 


\section{OVERVIEW OF DFIG AND SDBR CONTROL}

\section{A. DFIG Control}

The control block of the DFIG rotor side converter (RSC), the grid-side converter (GSC), and the SDBR control system is shown in Fig. 5.

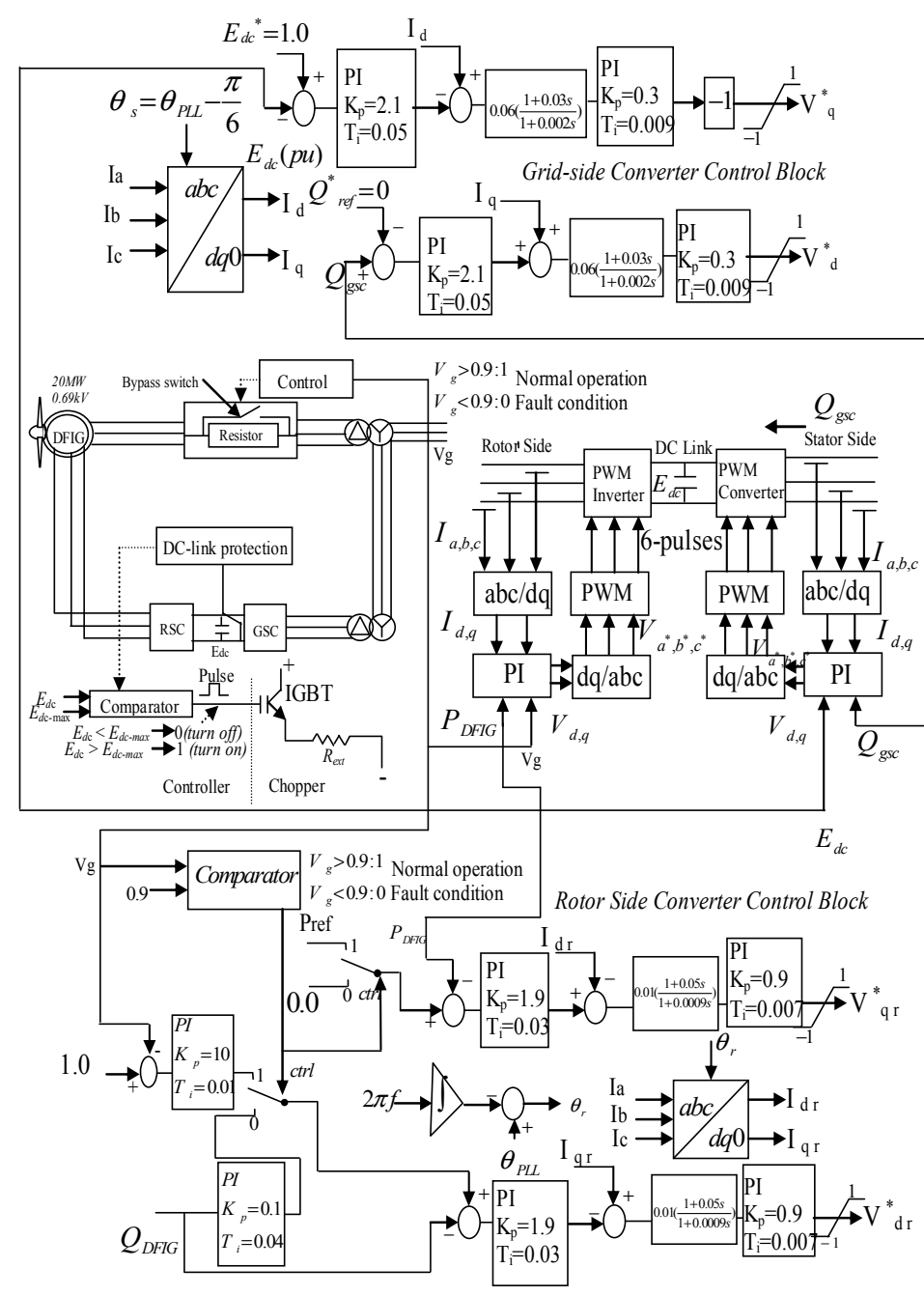

Fig. 5 Control block of DFIG and SDBR

In Fig. 5, the rotor side converter controls the terminal (grid) voltage to 1.0pu. The d-axis current controls the active power, while the q-axis current controls the reactive power. After dq0-to-abc transformation, $V_{d r}{ }^{*}$ and $V_{q r}{ }^{*}$ are sent to the PWM signal generator and $V^{*}{ }_{a b c}$ are the three-phase voltages reference for the rotor side converter as shown in the converter configuration circuit.

Fig. 5 also shows the control block for the GSC control of the DFIG, where phase lock loop (PLL) provides the angle $\theta_{P L L}$ and $\theta_{s}$ is the effective angle for the abc-to-dq0 (and dq0-to-abc) transformation. The GSC of the DFIG system is used to regulate the DC-link voltage $\left(E_{d c}\right)$ to $1.0 \mathrm{pu}$. The daxis current controls the DC-link voltage, while the q-axis current controls the reactive power of the grid side converter. After a dq0- to-abc transformation, $V_{q}{ }^{*}$ and $V_{d}{ }^{*}$ are sent to the pulse width modulation (PWM) signal generator. Finally, $V_{a b c}{ }^{*}$ voltage reference, are sent to the GSC for the IGBT's switching.

\section{B. SDBR Control}

The SDBR control is done by inserting a resistor in the stator of the DFIG during a fault, and thus, the terminal voltage of the generator increases, mitigating the destabilizing depression of electrical torque and power. The schematic arrangement and control strategy is shown in Fig. 5. Either a bypass switch or a circuit breaker could be used for the SDBR control strategy. But the cost of a bypass switch is less expensive than that of a circuit breaker. The bypass switch for the SDBR is normally on, but when voltage dip below $0.9 \mathrm{pu}$ occurs due to a grid fault, it opens to allow current pass through a small series resistance. Current then begins to flow through the inserted resistor. When voltage is recovered above a certain specified level, the bypass switch closes and the stator circuit restores to its normal state. During the short insertion period, the energy is dissipated in the resistor, raising its temperature. The resistor should be selected according to its temperature limit and the maximum energy which can be dissipated during the short period.

In the SDBR control strategy, the high voltage will be shared by the resistance because of the series topology. Therefore, the induced overvoltage may not lead to the loss of converter control. The SDBR not only control the rotor overvoltage which could cause the RSC to lose control, but limits high rotor current more significantly. In addition, the rotor current limitation can also reduce the charging current to the DC-link capacitor, hence avoiding DC-link overvoltage which could damage the DFIG power converter. The SBDR can also balance the active power of the DFIG, and thus, can also improve the DFIG wind generator stability during a fault. Also, the SDBR will increase the generator output and therefore reduce its speed increase during a voltage dip. This effect would improve the post fault recovery of the DFIG system because the SDBR controls and improves the rotor speed acceleration during a grid fault.

\section{EFFECT OF THE MAGNITUDE AND THE SWITCHING TIME OF SDBR}

During a grid fault, the SDBR mitigates acceleration of wind generators more strongly. This effect is a result of the additional power, some of which is exported into the grid and the remainder is dissipated in the SDBR resistor [16]. The energy dissipated by SDBR determines its size and cost. This energy can be optimized by changing the switch-out time. The switch-in time, on the other hand, should be as short as possible to maximize its speed limitation effect. Two control 
strategies by using a bypass switch and a circuit breaker are investigated to show the effect of the SDBR magnitude, along its insertion time and duration of operation, on the stability of the wind generator. Different values of SDBR resistance, $0.05 \mathrm{pu}, 0.1 \mathrm{pu}$ and $0.15 \mathrm{pu}$, are used in the analysis which will be shown in the simulation results. According to the simulation results, the small SDBR resistance of $0.05 \mathrm{pu}$ gives a better response. Hence this value is used to show the effect of the insertion time and duration of operation of the SDBR, as summarized in Table I.

Table I

Considered cases of SDBR switching time

\begin{tabular}{|c|c|c|c|}
\hline $\begin{array}{c}\text { Duration of } \\
\text { SDBR insertion } \\
\text { after fault } \\
\text { initiation (ms) }\end{array}$ & $\begin{array}{c}\text { Switch-in } \\
\text { time(ms) }\end{array}$ & $\begin{array}{c}\text { Switch-out } \\
\text { time(ms) }\end{array}$ & $\begin{array}{c}\text { Duration of } \\
\text { operation(ms) }\end{array}$ \\
\hline 20 & 120 & 200 & 80 \\
\hline 50 & 150 & 250 & 100 \\
\hline 80 & 180 & 300 & 120 \\
\hline
\end{tabular}

As will be shown in the simulation results in section VI, the quicker the insertion time of the SDBR and the shorter its duration of operation, the better the stability performance of the DFIG during a grid fault.

\section{Simulation Results}

Simulation analyses for a three phase fault were performed for the two proposed schemes, with different magnitude of SDBR (scheme 1) and different insertion time and duration of operation of SDBR (scheme 2) The fault occurs at $100 \mathrm{~ms}$ where the DFIG wind turbine was operating at its rated power, under a wind speed of $15 \mathrm{~m} / \mathrm{sec}$. The circuit breakers on the faulted lines are opened at $0.2 \mathrm{sec}$, and finally, at $1.0 \mathrm{sec}$, the circuit breakers are re-closed. The results are shown in Figs 612.

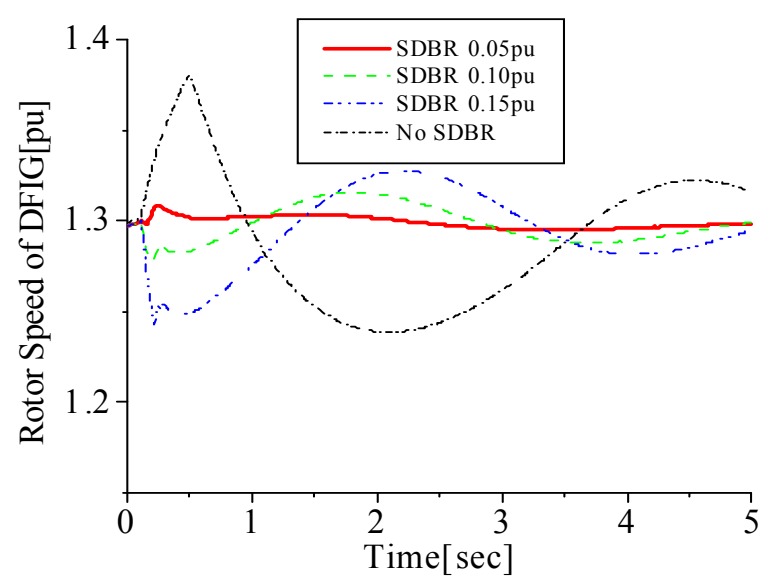

Fig. 6 Rotor speed of DFIG

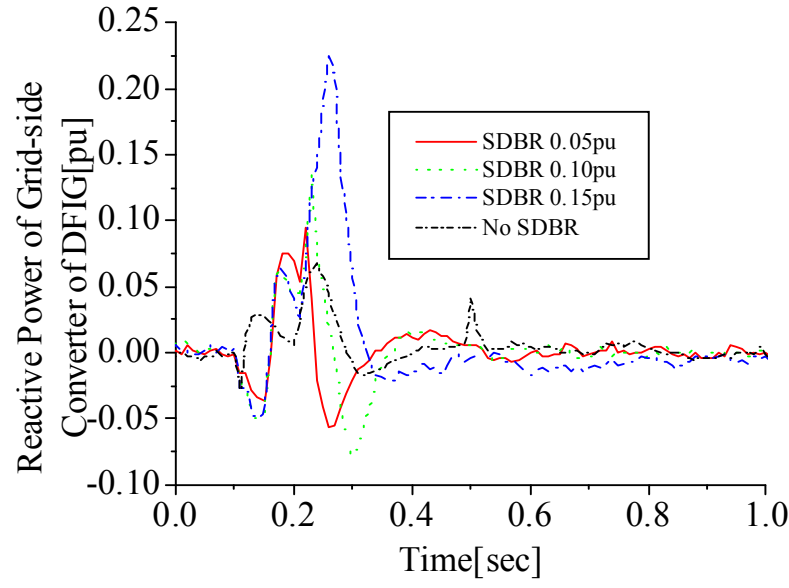

Fig. 7 Reactive power of grid-side converter of DFIG

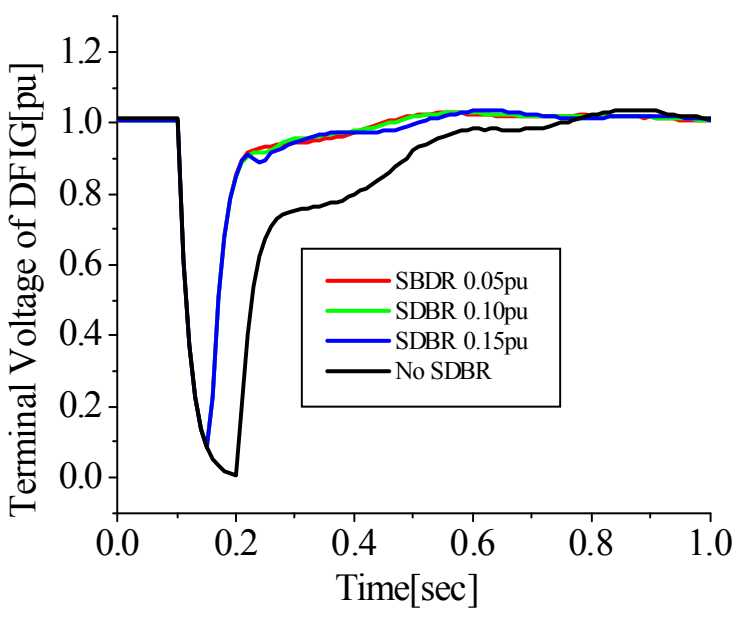

Fig. 8 Terminal voltage of DFIG

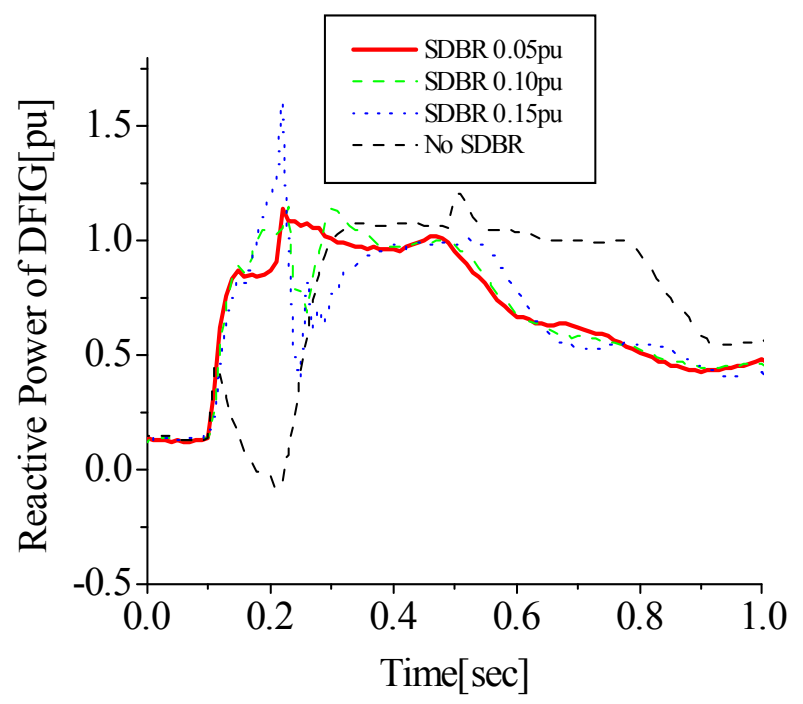

Fig. 9 Reactive power of DFIG 


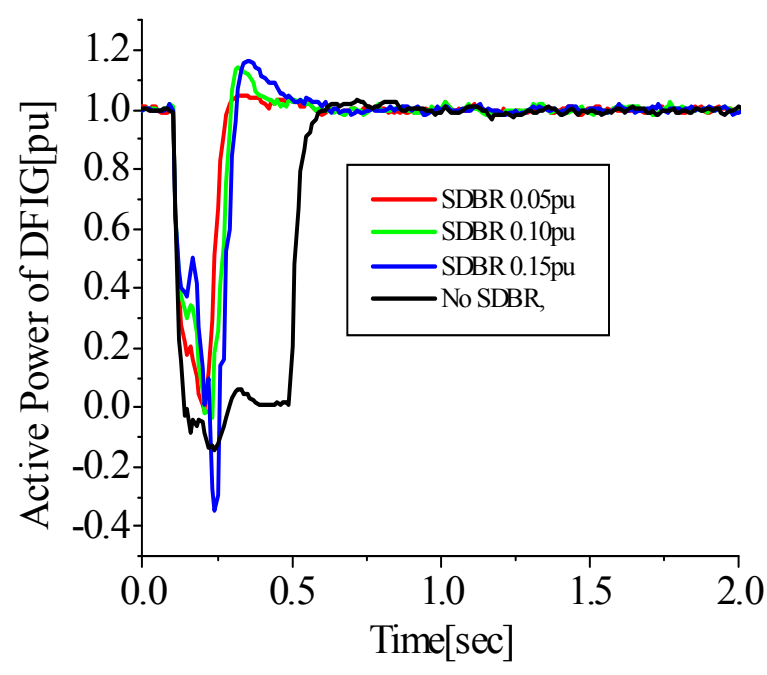

Fig. 10 Active power of DFIG

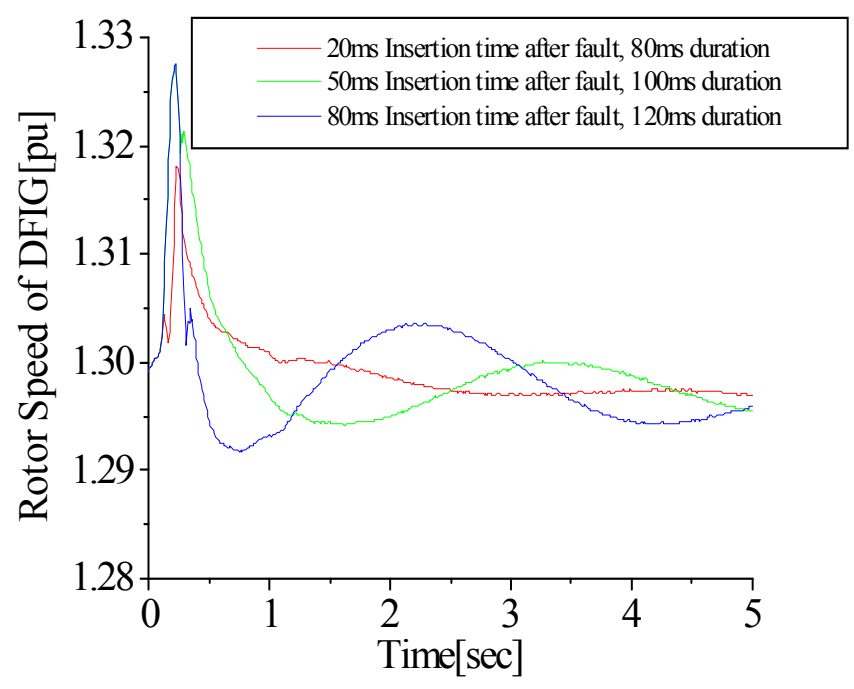

Fig. 11 Rotor speed of DFIG

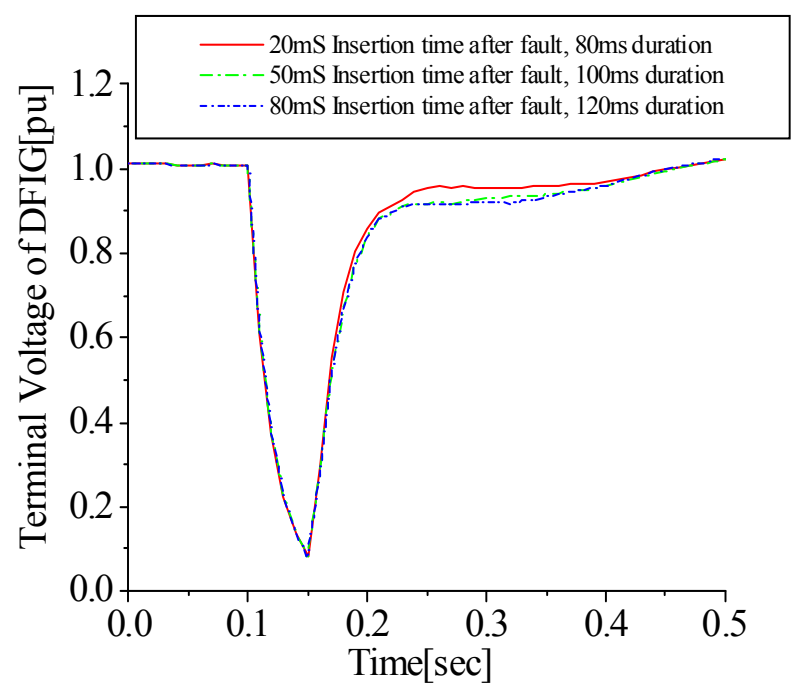

Fig. 12 Terminal voltage of DFIG
Figs. 6-10 show the effect of the SDBR magnitude on the performances of DFIG during the grid fault. It is seen from Figs. 6 and 7 that the SDBR with $0.05 \mathrm{pu}$ resistance gives better performances for the DFIG rotor speed and reactive power of the grid-side converter. Fig. 8 shows that the SDBR can improve the terminal voltage of the DFIG during the fault. It is seen from Figs. 9 and 10 that, in the cases with high SDBR resistance, there appears a peak in the responses of the reactive power and active power of the DFIG, while smaller SDBR gives a better response.

The effects of the insertion time and duration of operation of the SDBR on the performance of DFIG are shown in Figs. 11 and 12. The quicker the insertion time and the shorter the duration of operation of the SDBR are, the better responses can be obtained in the rotor speed and terminal voltage of the DFIG during the grid fault.

\section{CONCLUSION}

The effects of the resistance magnitude, duration of operation and insertion time of a series dynamic braking resistor (SDBR) in a wind generator during grid fault have been investigated. The SDBR was connected to the stator side of a doubly fed induction generator (DFIG). Two control strategies using a bypass switch and a circuit breaker have been used for the SDBR. A DC-link chopper braking resistor has also been used in the proposed system to protect the DClink voltage during grid fault. It was reported that the size of the SDBR should be carefully determined because large value may affect the system performance during grid fault. It was also reported that, the shorter the time from fault initiation and duration of operation of the SDBR, the better the stability of the DFIG. Hence, it is concluded that the proposed SDBR can effectively improve the stability and fault ride through of DFIG.

\section{ACKNOWLEDGMENT}

The authors would like to acknowledge Japan Gas Corporation (JGC) and The Petroleum Institute, Abu Dhabi, UAE for their kindly support in this work.

\section{REFERENCES}

[1] G. Pannell, D. J. Atkinson, and B. Zahawi, "Minimum-threshold crowbar for a fault ride through grid code compliant DFIG wind turbine," IEEE Trans. Energy Conver., vol. 25, no. 3, pp. 750-759, September, 2010.

[2] J. Morren and S. W. H. de Haan, "Short-circuit current of wind turbines with doubly fed induction generator," IEEE Trans. Energy Convers., vol. 22, no. 1, pp. 174-180, March, 2007.

[3] P. S. Flannery and G. Venkataramann, "A fault tolerant doubly fed induction generator wind turbine using parallel grid side rectifier and series grid side converter," IEEE Trans. Power Electronics, vol. 23, no. 3, pp. 1126-1135, May, 2008. 
[4] M. S. Vicatos and J. A. Tegopoulous, "Transient state analysis of a doubly fed induction generator under three phase short circuit," IEEE Trans. Energy Convers., vol. 6, no. 1, pp. 62-68, March 1991.

[5] J. Lopez, E. Gubia, P. Sanchis, X. Roboam, and L. Marroyo, "Wind turbines based on doubly fed induction generator under asymmetrical voltage dips, " IEEE Trans. Energy Convers., vol. 23, no. 1, pp. 321-330, March, 2008.

[6] M. Rodriguez, G. Abad, I. Sarasola, and A. Gilabert, "Crowbar control algorithms for doubly fed induction generator during voltage dips," Presented at the $11^{\text {th }}$ Eur. Conf. Power Electronics Application, Dresden, Germany, September, 11-14, 2005.

[7] J. Yao, H. Li., Y. Liao, and Z. Chen, "An improved control strategy of limiting the DC-link voltage fluctuation for a doubly fed induction wind generator," IEEE Trans. Power Electronics, vol. 23, no. 3, pp. 12051213, May, 2008.

[8] R. Takahashi, J. Tamura, M. Futami, M. Kimura and K. Idle, "A New Control Method for Wind Energy Conversion System Using Double Fed Synchronous Generators," IEEJ Trans. Power and Energy, Vol.126, No.2, pp.225-235, 2006 (in Japanese).

[9] M. B. C. Salles, J. R. Cardoso, A. P. Grilo, C. Rahmann, and K. Hameyer, "Control strategies of doubly fed induction generators to support grid voltage," In the proceedings of IEEE International Electric Machines and Drives Conference - IEMDC 2009, Miami, FL, USA, May, 2009.

[10] K. E. Okedu, S. M. Muyeen, R. Takahashi, and J. Tamura, "Comparative study between two protection schemes for DFIG-based wind generator," International Conference on Electrical Machines and Systems (ICEMS), Seoul, South Korea, 2010, available online IEEE Explorer.

[11] H. Awad, J. Svensson, and M. Bollen, "Mitigation of unbalanced voltage dips using static series compensator," IEEE Trans. Power Electronics, vol. 19, pp. 837-846, May, 2004.

[12] R. G. de Almeida, J. A. Lopez, J. A. L. Barreiros, "Improving power system dynamics behavior through doubly fed induction machines controlled by static converter using fuzzy control," IEEE Trans. Power System, vol. 19, no. 4, pp. 1942-1950, November, 2004.

[13] A. O. Ibrahim, T. H. Nguyen, D. Lee, and S. Kim, "Ride through strategy for DFIG wind turbine systems using dynamic voltage restorers," Proceedings IEEE-ECCE (Energy Conversion Congress and Exposition), California, USA, 2009.

[14] Q. Wei, G. K. Venayagamorthy, and R. G. Harley, "Real-time implementation of a STATCOM on a wind farm equipped with doubly fed induction generators, "IEEE Trans. Ind. Appl., vol. 45, no.1, pp. 98107, January, 2009.

[15] A. Causebrook, D. J. Atkinson, and A. G. Jack, "Fault ride through of large wind farms using series dynamic braking resistors," IEEE Trans. Power Systems, vol. 22, no. 3, pp. 966-975, March, 2007.

[16] J. Yang, E. Fletcher, and J. O'Reilly,'A series dynamic resistor based converter protection schemes for doubly fed induction generator during various fault conditions," IEEE Tran. Energy Convers. Vol. 25, no. 2, pp. 422-432, June, 2010.

[17] W. Park, B. C. Sung, and J. W. Park, "The effect of SFCL on electric power grid with wind turbine generation system," IEEE Trans. Applied Superconductivity, vol. 20, no. 3, pp. 1177-1181, June, 2010.

[18] X. Yan, G. Venkataramanan, and Y. Wang, "Grid fault tolerant operation of DFIG wind turbine generator using a passive resistance network," Proceedings IEEE-ECCE (Energy Conversion Congress and Exposition), California, USA, 2009.

[19] A. Petersson, S. Lundberg, and T. Thiringer, "A DFIG wind turbine ride through system influence on energy production," Wind Energy Journal, vol. 8, pp. 251-263, 2005.

[20] “PSCAD/EMTDC Manual," Manitoba HVDC Research Center, 1994.

[21] K.E. Okedu, S. M. Muyeen, R. Takahashi, and J. Tamura, "Participation of FACTS in stabilizing DFIG with crowbar during grid fault based on grid codes," IEEE-GCC Conference and Exhibition Dubai, UAE, Feb. 2011, available online IEEE Explorer.

[22] K. E. Okedu, S. M. Muyeen, R. Takahashi, and J. Tamura, "Stabilization of wind farms by DFIG-based variable speed wind generators," International Conference on Electrical Machines and Systems (ICEMS), Seoul, South Korea, 2010, available online IEEE Explorer.

[23] S. Santos, and H. T. Le, "Fundamental Time-Domain Wind Turbine Models for Wind Power Studies," Renewable Energy, Vol. 32, pp. 24362452, 2007.

[24] O. Wasynczuk, D. T. Man, and J. P. Sullivan, "Dynamic Behavior of a Class of Wind Turbine Generator during Random Wind Fluctuations,"
IEEE Trans. on Power Apparatus and Systems, Vol. PAS-100, No.6, pp.2837-2845, 1981. 